\title{
Comunicação, educação e vigilância popular em saúde em tempos de COVID-19 - a experiência das comunidades de Niterói, RJ
}

Paula Kwamme Latgé, Daniela Nunes Araujo, Aluísio Gomes da Silva Junior

\section{RESUMO}

O acesso à internet, renda mínima e à segurança alimentar no contexto do coronavírus (COVID-19) evidenciam a fragilidade social. Neste contexto, um grupo de jovens comunicadores da cidade de Niterói no Rio de Janeiro foi mobilizado pela OSC BemTV Educação e Comunicação para compor um capaz de enfrentar as dificuldades de acesso à internet e construir coletivamente a checagem de informações, combate a notícias falsas, capilarização do acesso e fortalecimento das políticas e estratégias para conter a exponencialidade da contaminação comunitária.

Palavras-chave: Comunicação Comunitária; Comunicação Popular; Jovens Comunicadores; COVID-19; Educonectar.

\section{ABSTRACT}

Access to the internet, to the minimum income and to the food security in the context of the coronavirus (COVID-19) shows us the social fragility. In this context, a group of young communicators from the city of Niterói, in Rio de Janeiro, was mobilized by OSC BemTV Educação e Comunicação to compose one which is capable of facing the difficulties of accessing the internet and collectively assemble information checking, to fight against fake news, to widen the access and strengthen policies and strategies and to control the exponential growth of community contamination.

Keywords: Community Communication; Popular Communication; Young Communicators; COVID-19; Educonectar.
Revista da Rede APS 2020

Publicada em: 09/06/2020

DOI:10.14295/aps.v2i2.110

Paula Kwamme Latgé

(BEM TV, Universidade Federal Fluminense, Niterói, Rj, Brasil)

Daniela Nunes Araujo (BEM TV, Niterói, RJ, Brasil)

Aluísio Gomes da Silva Junior (Universidade Federal Fluminense, Niterói, RJ, Brasil)

Correspondência para:

Paula Kwamme Latgé paulalatge@gmail.com

Daniela Nunes Araujo dani@bemtv.org.br

Aluísio Gomes da Silva Junior agsilvaj@gmail.com 


\section{INTRODUÇÃO}

O que pode significar o imperativo "fique em casa"? Ordenamento repetido intensamente desde março de 2020, quando o novo coronavírus iniciou seu triste percurso espalhando um lastro de sofrimento e morte. Essa indicação de permanência na esfera privada, tão necessária ao momento atual, na direção da não contaminação, da preservação da vida, recolhimento de cada um em nome de todos, deixará marcas na nossa estrutura social. Faz-se fundamental, por mais difícil que essa reflexão possa parecer, refletir sobre os possíveis efeitos de se regular a circulação de corpos humanos, limites físicos com efeitos subjetivos e políticos.

Orientações em saúde, ordenamentos sociais, respeito as orientações sanitárias, regras a serem cumpridas, que quando não atendida fica explicitada como desobediência. Sem dúvida a COVID-19, doença provocada pelo novo coronavírus, exige que resguardemos as pessoas. Entretanto, por mais que pareça sensata a permanência em casa, não é óbvia e muito menos igual para todos. A adoção de medidas como a utilização de máscaras de proteção, álcool em gel ou orientação de lavar as mãos com água e sabão, fica distante de grande parte da população brasileira, moradores de um país onde 35 milhões de habitantes não tem acesso a água tratada e apenas $53 \%$ da população tem acesso à coleta de esgoto ${ }^{2}$, isto é, aproximadamente 100 milhões de brasileiros não têm acesso a esse serviço. A maior parte deste contingente está concentrada em regiões afastadas e favelas situadas em grandes centros urbanos.

Os direitos sociais básicos, dispostos no artigo 6으 da Constituição Federal de 1988, (educação, saúde, alimentação, trabalho, moradia, transporte, lazer, segurança, previdência social, proteção à maternidade e à infância, assistência aos desamparados), sempre foram negados a essa parcela da população, a quem hoje se ordena regras sanitárias como ficar em casa, lavar as mãos, além do uso de máscaras.
As máscaras, por exemplo, que hoje assumem a função de proteção individual, devem ser vistas à luz de seus possíveis significados para a população negra e em seu embate cotidiano com a política de segurança pública no Estado do Rio de Janeiro. Nesse sentido, o que realmente muda e para quem com o novo coronavírus? Quem vive sem garantia da proteção social, como deve ressoar a afirmação "Fique em Casa?"

Tendo essas questões como guia e a insuficiência de normativas como instrumento de proteção para a população historicamente mais vulnerabilizada, é que se desenha o trabalho dos Jovens Comunicadores em Saúde, experiência marcada por quatro eixos fundamentais: Comunicação Comunitária, Educação, Vigilância Popular em Saúde e Transferência de Renda, considerando o impacto da pandemia para os territórios no âmbito de atuação da OSC BemTV Educação e Comunicação, situada em Niterói, Rio de Janeiro. Entende-se este trabalho a partir da perspectiva de moradores participantes do coletivo "Jovens Comunicadores em saúde" e suas dificuldades, onde ficar em casa se torna uma tarefa complexa e desafiadora, seja pela ausência de saneamento e condições de manutenção da renda, seja pela falta de acesso à informações claras e de linguagem acessível.

Este artigo está dividido a partir do processo de construção da ação em rede para formação de jovens e criação das estratégias para construção de alternativas dotadas de sentido àqueles que já não conseguem distinguir informações de falsas notícias ou notícias tendenciosas e que neste processo se propõem a atuar como comunicadores comunitários. Serão apresentadas as bases conceituais que 
permeiam a ação de educonectar ${ }^{1}$, conectar a partir da construção de conhecimentos, partilhando o comum e fomentando o sentido de investigação e trocas.

\section{DA FRÁGIL CONECTIVIDADE À CONEXÃO}

\section{DE SENTIDOS}

As comunidades e favelas, historicamente abandonadas pela administração pública, tornam-se ainda mais vulneráveis diante da epidemia do novo coronavírus, devido a fatores como a ausência de saneamento básico e da insegurança alimentar, somam-se ao subemprego ou ao emprego informal que distancia desta grande parcela da população as condições necessárias para acessar a seguridade social.

No enfrentamento à COVID-19 a comunicação pode ocupar um lugar estratégico se não limitada a transferência de informação.) Araújo e Cardoso (2007) ressaltam que pela comunicação é possível ser agente de "manutenção ou transformação da realidade". Indicando como conceito de renovação na comunicação e saúde Araújo (2003) se apropria do conceito de polifonia de Bakthin, entendendo-o não somente como transmissão de conteúdos acabados, e sim espaço de produção/negociação de sentidos.

Considerando as condições particulares e a lógica de produção de sentidos que carregam uma multiplicidade de vozes é que se consolida a experiência de Jovens Comunicadores, através de um conjunto de ações de comunicação popular em favelas para ampliar acesso as informações seguras sobre direitos, saúde e prevenção à COVID-19.

1 - Educonexão: Termo teórico prático que propões a construção de processos orgânicos e co-elaborativos para a potencialização e apoio à processos coletivos de construção de conhecimentos. Uma conexão educativa a partir da integração de ferramentas
Por meio de compartilhamento por redes sociais e alcançando mais de 120 mil pessoas simultaneamente, 500 jovens atuam em comunidades com maior densidade populacional e menor renda de Niterói e São Gonçalo no processo formativo, objetivando capilarizar informações em saúde, em especial sobre o novo coronavírus, formando jovens comunicadores para checagem, adaptação, produção e compartilhamento de informações em saúde. Ainda que a atenção prioritária seja informações em saúde com foco no novo coronavírus, elementos vinculados ao acesso a direitos que envolve outras políticas públicas deverão estar no radar dos Jovens comunicadores.

Em tempos de "isolamento social" o desafio inicial foi buscar uma lógica onde afastamento físico e ferramentas informacionais não representassem distância e sim proximidade, aproximações de realidades, discursos, expectativas e compromissos instituídos coletivamente. Foi levada em conta que a política de democratização de acesso à internet garante acesso à $70 \%$ da população, segundo dados da pesquisa TIC domicílios 2018. Segundo a mesma pesquisa, $85 \%$ dos usuários de Internet da classe $D$ e $E$ acessam a rede exclusivamente pelo celular, $2 \%$ apenas pelo computador e $13 \%$ se conectam tanto pelo aparelho móvel quanto pelo computador.

Desta forma, optou-se pelo celular como ferramenta central para os processos formativos e ainda produção/adaptação e transmissão de conteúdo. $O$ processo formativo envolve encontros em vídeo-chamada com transmissão ao vivo/webinário, possibilitando interação entre jovens e mediadores. A não escolha pelo termo virtual é consciente, partindo do significado que o virtual é o que não tem efeito real, que existe em potência. Por isso, entende-

digitais somadas à práticas orgânicas e epistemológicas de polifonia de saberes. 
se sua inadequação para o sentido do processo formativo, que incide diretamente no real em toda sua realização. Os encontros articulam conteúdos teóricos e atividades práticas, sendo cada jovem comunicador responsável por construir uma lista de transmissão composta por atores locais de sua comunidade.

Após o processo de formação, coletivamente, os jovens produzem/adaptam materiais sobre saúde com ênfase em direitos sociais, saúde e estratégias de enfrentamento à COVID-19.

O encontro é ponto central do processo: ele se utiliza de tecnologias para gerar aproximações, conexões co-elaborativas de novas possibilidades de existências (menos constrangidas pelo poder, medo da morte e da vida) e pela hegemonia que tem definido a validade dos discursos. Este encontro acaba por ser um amplificador de potências, destituindo lugares de poder e por meio de muitas conexões a serviço da circulação de informações sobre o novo coronavírus, e principalmente atuando contra formas de opressão que abafam sofrimentos da classe popular.

Partindo do entendimento que processos de opressão vêm inundados de racismo e preconceitos sociais, e que com a COVID-19 não seria diferente, a proposta de ação com os jovens comunicadores foi estruturada de forma a montar redes territorializadas/comunitárias de comunicação popular tendo como base a Frente Papagoiaba de Promoção dos Direitos da Juventude Negra, constituída por movimentos e organizações sociais de Niterói e São Gonçalo. São movimento sociais, instituições e jovens comunicadores buscando construir aproximações comunitárias em tempos de isolamento e apagamento do espaço comum. Isso, segundo Arendt (2007), poderia significar o apagamento do espaço político, considerando que para autora espaço público é condição fundamental da atividade política.

\section{DOS DIÁLOGOS - PASSAGEM DA VIGILÂNCIA SANITÁRIA PARA VIGILÂNCIA POPULAR}

O processo dos Jovens Comunicadores tem como base uma comunicação que não esteja reduzida a uma transmissão de informação seca, sem retorno, o que se almeja com produções próprias e adaptações de informações genéricas em conteúdos situados em pessoas e lugares. É a construção de interlocuções entre jovens, moradores, atores públicos (profissionais da Atenção Primária e Proteção Social Básica; gestores públicos e profissionais das instituições de ensino) para ampliação do acesso aos serviços e benefícios, troca de informação, esclarecimento de dúvidas e acompanhamento das políticas públicas e ações emergenciais apresentadas pelo poder público como resposta a pandemia da COVID-19.

"Mão" e "contramão" que amplia a lógica do cumpra-se, do ordenamento, para outra dimensão do cuidado e da proteção social. Não mais uma obediência ou desobediência ao "Fique em casa", uma apropriação do que é público para além do espaço físico, um vetor duplo orientado da Estado ao cidadão, e do cidadão ao Estado. Para além das determinações da vigilância sanitária que visa "eliminar, diminuir ou prevenir riscos à saúde e de intervir nos problemas sanitários decorrentes do meio ambiente, da produção e circulação de bens e da prestação de serviços de interesse da saúde" (BRASIL, 1990), o que se propõe com os Jovens Comunicadores é uma vigilância civil da saúde, referenciado pelo educador Victor Vincent Valla em meados dos anos 1990 e, no correr da experiência, agregou processos como a construção compartilhada do conhecimento e a ouvidoria coletiva. Realizada com a população, alicerçada na cultura local e na educação popular de Paulo Freire, a vigilância civil pode representar a vertente da vigilância em saúde que corporifique a participação popular e contribua para a transformação social, 
complementando a tradicional vigilância epidemiológica. (SEVALHO. 2016, p. 612)

$\mathrm{O}$ que se pretende construir junto dos Jovens Comunicadores e seus territórios é um banco de "dados alternativo", nas palavras de Valla, uma "epidemiologia do cotidiano". Em tempo de pandemia da COVID-19, onde as dúvidas sufocaram as certezas e discursos circulam entre notícias falsas/verdadeiras, com consequências concretas nas vidas das pessoas, a construção de um diagnóstico participativo pode ser ponto estruturante para produção de respostas mais aceitáveis e efetivas para a produção de cuidado. Um cuidado que não despreza a realidade, mas dialoga com as possibilidades de sujeitos, territórios e história de cada um e também de todos. Uma contagem para além da numérica.

\section{DE ENTREGADORES DE APLICATIVOS AO FIQUE EM CASA}

Além da contagem numérica existe um lugar, com uma polifonia de sons e sonhos, limites e potencialidades. Um lugar nem sempre tranquilo, onde jovens precisam defender suas condições materiais de existência, e que muitas vezes têm sua força de trabalho "comprada" por aplicativos de delivery, e nessa circulação sem direitos garantidos como fica comando categórico par ficar em casa? Como forma de responder a essa circulação, também imperiosa, afinal condições materiais, são condições de vida. Considerando que grande parte dos jovens de camadas populares trabalha com aplicativos de delivery, como medida voltada para contribuição do afastamento social, os jovens comunicadores recebem uma bolsa-auxílio afiançando a segurança de renda e contribuindo diretamente para medidas preconizadas pelas autoridades sanitárias de afastamento social.

De forma geral, com medo e também com esperança a aposta na comunicação que transforma, que amplia espaços, que disputa discursos, faz parte dessa experiência de jovens comunicadores comunitários, um desenho que se utiliza de ferramentas informacionais para gerar proximidades, não uma educação à distância, uma conexão educativa, um processo de co-elaboração de vários, que acreditam que o cuidado só se faz viável em redes que atuam em "territórios existenciais". Um território existencial não se refere a um território como um ponto em um mapa, estático e já delimitado em si. Mais que uma delimitação espacial, um território existencial é uma localização espaçotemporal. Ele se define a partir de uma localização espacial que é configurada no tempo, ou seja, ele é um território em processo, em constante processo feitura. (MACERATA et. al., 2014, p. 922)

As formas de existir e as possibilidades de existências fazem-se centrais no processo de cuidado, para que a dureza do momento agravada pela COVID-19, e o enquadramento das repostas políticas, não subtraiam a realidade mascarando a desigualdades históricas, afinal como declama Caetano Veloso é preciso "olharmo-nos nos na intacta retina" nossas localizações espaço-temporal. 


\section{NOTAS E REFERÊNCIAS}

2 - Sistema Nacional de Informações sobre Saneamento - SNIS 2018 http://www.snis.gov.br/diagnosticoanual-agua-e-esgotos/diagnostico-dos-servicos-de-agua-e-esgotos-2018 Visitado em 03/05/20

ARAÚJO I. S, CARDOSO J. M. Comunicação e Saúde. Rio de Janeiro: Editora FIOCRUZ, 2007. 152 p. (Coleção Temas em Saúde)

ARAÚJO, I. Razão polifônica: a negociação de sentidos na intervenção social. Perspectivas em Ciência da Informação, Belo Horizonte, v. 8, p. 46-57, jul./dez. 2003. Número especial.

ARENDT, Hannah. A condição humana. Tradução de Roberto Raposo, posfácio de Celso Lafer. - 10. Ed Rio de Janeiro: Forense Universitária, 2007

MACERATA, lacã; SOARES, José Guilherme Neves; RAMOS, Julia Florêncio Carvalho. Apoio como cuidado de territórios existenciais: Atenção Básica e a rua. Interface (Botucatu), Botucatu, v. 18, supl. 1, p. 919930, 2014. Disponível em <http://www.scielo.br/scielo.php?script=sci_arttext\&pid=S141432832014000500919\&Ing=pt\&nrm=iso>. acessos em 06 maio 2020. https://doi.org/10.1590/180757622013.0210 .

SEVALHO, Gil. Apontamentos críticos para o desenvolvimento da vigilância civil da saúde. Physis, Rio de Janeiro, v. 26, n. 2, p. 611-632, June 2016. Available from <http://www.scielo.br/scielo.php?script=sci_arttext\&pid=S0103-

73312016000200611\&lng=en\&nrm=iso>. access on 06 May 2020. http://dx.doi.org/10.1590/S010373312016000200014 